\title{
Presumptive identification and antibiotic susceptibility of group B streptococci
}

\author{
A. M. M. JOKIPII AND LIISA JOKIPII \\ From the Department of Serology and Bacteriology, University of Helsinki, Helsinki, Finland
}

SYNOPSIS The comparative performance of three presumptive identification tests for group $\mathbf{B}^{\varnothing}$ haemolytic streptococci was investigated, using 371 different clinical isolates of group B strepto- $\infty$ cocci. Hippurate was hydrolysed by $96.1 \%$, the CAMP reaction was positive in $95.0 \%$, and pigment was produced by $97 \cdot 3 \%$. A combination of any two tests would have detected over $99.8 \%$. On bile ${ }^{\omega}$ esculin agar $99.0 \%$ were able to grow, but none hydrolysed esculin; $5.1 \%$ were susceptible to 은 bacitracin. The minimum inhibitory concentrations of five antibiotics for 279 group B streptococci $\overrightarrow{-}$ were determined. All were susceptible to penicillin G, ampicillin, cephalothin, and erythromycin, while $80 \%$ were resistant to tetracycline. The MIC distributions were independent of the results of any identification test.

The importance of group B $\beta$-haemolytic streptococci as human pathogens, especially during the neonatal period, is well known (Duma et al, 1969; Eickhoff, 1972). Newborns acquire the organism during passage through the birth canal; it has been suggested, therefore, that all pregnant women should be screened for group B streptococci and, together with their husbands, treated if colonized by the organism (Franciosi et al, 1973). Screening for group B streptococci may, therefore, be necessary for diagnostic and epidemiological purposes. Presumptive identification schemes are required for this, since it may not be feasible in many clinical laboratories to group all streptococci serologically.

The ability to hydrolyse sodium hippurate (Ayers and Rupp, 1922) and the production of the CAMP factor (Christie, Atkins, and Munch-Petersen, 1944 -from whom the name is derived), which lyses ruminant erythrocytes treated with staphylococcal $\beta$-toxin, differentiate group B streptococci from most other serological groups. Recently, pigment production in anaerobic conditions has been used as a distinctive characteristic of group B $\beta$-haemolytic streptococci (Fallon, 1974). We have subjected fresh human isolates of group B haemolytic streptococci to these identification tests to determine their performance in identifying group B streptococci in the practice of a clinical microbiological laboratory. In addition, they have been tested for susceptibility to bacitracin (Maxted, 1953) and for growth and

Received for publication 30 December 1975 esculin hydrolysis on bile esculin agar (Swan, 1954), characteristics of group A and group D streptococci, respectively. We also determined the in vitro susceptibility of group B streptococci to five antibiotics.

\section{Material and methods}

SELECTION OF STRAINS

Over a period of 15 months, $\beta$-haemolytic streptococci, isolated in significant numbers from clinical specimens taken for routine bacteriological examina-융 tion, were grouped serologically with the technique :of Swift et al (1943) using commercial antisera (Behringwerke AG, Marburg-Lahn, Germany). Al- $\delta$ together 371 different isolates of group B streptococci were obtained; 166 of the specimens were 0 from various departments of Helsinki University Central Hospital and 205 from general practitioners in the Helsinki area. The strains were reported as probable pathogens in the conditions from which or they were isolated: vaginitis, Bartholinitis, ureth- N ritis, bacteriuria, pharyngitis, rhinitis, sinusitis, ్ㅗㅇ otitis media, wound infection, or abscess (Eickhoff ${ }^{\omega}$ et al, 1964; Duma et al, 1969; Jelínková et al, 1970; Eickhoff, 1972).

HIPPURATE HYDROLYSIS

The hydrolysis of sodium hippurate was determined ${ }^{\circ}$ as described by Facklam et al (1974). The test strain was inoculated into $5 \mathrm{ml}$ of heart infusion broth $\frac{\vec{\Phi}}{\mathbb{D}}$ (Difco, Detroit, Michigan) containing sodium hip- 음 purate, $10 \mathrm{mg} / \mathrm{ml}$. After incubation at $35^{\circ} \mathrm{C}$ for 48 
hours, the cultures were centrifuged and the supernatant was tested for benzoate with ferric chloride reagent.

\section{CAMP REACTION}

The production of CAMP factor was assayed by the modification of Barnum (1950) on $10 \%$ ox blood agar plates. A $\beta$-toxin-producing staphylococcus was inoculated as a diagonal on a plate, and the streptococcal strain to be tested was streaked at right angles at a distance of $1-2 \mathrm{~mm}$ from the staphylococcus. After overnight incubation at $35^{\circ} \mathrm{C}$ the plates were examined for synergistic haemolysis, the CAMP reaction.

\section{PIGMENT PRODUCTION}

Test strains were inoculated on Columbia agar plates (Oxoid, London). After overnight incubation at $35^{\circ} \mathrm{C}$ anaerobically in the GasPak system, the presence or absence of reddish pigmentation of the colonies was recorded (Fallon, 1974).

\section{BILE ESCULIN AGAR}

Test strains were inoculated on bile esculin agar plates (Swan, 1954), and the parameters recorded after overnight and after 40 hours' incubation at $35^{\circ} \mathrm{C}$ were growth and the production in and around the colonies of a black colour, indicating esculin hydrolysis.

\section{ANTIBIOTIC SUSCEPTIBILITY}

Paper discs containing $\mathbf{0 . 2}$ IU of bacitracin were placed on densely streaked pure cultures of the streptococcal strains on blood agar plates, and the diameters of the inhibition zones were measured after overnight incubation at $35^{\circ} \mathrm{C}$. The minimum inhibitory concentrations (MIC) of penicillin G, ampicillin, cephalothin, erythromycin, or tetracycline were determined with the plate dilution method of Müller-Hinton agar (Difco) containing $5 \%$ horse blood using an inoculum-replicating device. The size of inoculum varied between $10^{5}$ and $10^{6}$ colony-forming units and the results were read after 24 hours' incubation at $35^{\circ} \mathrm{C}$.

\section{Results}

\section{IDENTIFICATION TESTS}

A summary of the results of tests on the 371 strains of group B haemolytic streptococci is shown in table I. Each of the three group B presumptive tests-hippurate hydrolysis, CAMP reactivity, and pigment production-gave about the same proportion of positive results. The theoretical number of strains giving a negative reaction in two tests simultaneously was $\mathbf{1 \cdot 3}$. One such strain was found;

\begin{tabular}{lccc}
\hline Test & \multicolumn{2}{c}{ Number of Strains } & \multicolumn{2}{l}{ Positive } \\
\cline { 2 - 3 } & \multicolumn{2}{c}{$\%$} \\
\cline { 2 - 3 } & Positive & Negative & \\
\hline Hippurate hydrolysis & 249 & 10 & 96.1 \\
CAMP reaction & 305 & 16 & 95.0 \\
Pigment production & 287 & 8 & 97.3 \\
Bacitracin susceptibility & 16 & 300 & 5.1 \\
Bile esculin agar & 290 & 3 & 99.0 \\
Growth & 0 & 293 & 0.0 \\
\hline Esculin hydrolysis & & & \\
\hline
\end{tabular}

Table I Reactions of group B $\beta$-haemolytic streptococci in presumptive identification tests

it failed to hydrolyse hippurate and was CAMP negative.

The frequency of bacitracin susceptibility was $5.1 \%$, the mean inhibition zone of the 16 strains being $13.3 \mathrm{~mm}$. The theoretical numbers of bacitracin susceptible strains giving a negative result in one of the three tests for group B streptococci was 0.5 for hippurate hydrolysis, 0.8 for CAMP reactivity, and 0.4 for pigment production. In fact, one of the 16 bacitracin susceptible strains was hippurate negative, two were CAMP negative, and all produced pigment.

Esculin hydrolysis was not detected in any of the 293 strains tested (table I), although all but three strains were able to grow on bile esculin plates, and the growth was not essentially weaker than that of enterococci. The theoretical number of strains failing to grow on bile esculin and giving an exceptional result in one of the four other tests was 0.5 , and one such result was found.

\section{ANTIBIOTIC SUSCEPTIBILITY}

All 279 different isolates of group B haemolytic streptococci tested were susceptible to penicillin $\mathbf{G}$, ampicillin, cephalothin, and erythromycin (table II). The MIC of tetracycline divided the strains into two major groups: $20 \%$ were inhibited by $0.8 \mu \mathrm{g} / \mathrm{ml}$ or less, $75 \%$ had a MIC of $50 \mu \mathrm{g} / \mathrm{ml}$ or higher, and only $5 \%$ were intermediate. No significant deviations from the MIC distribution of the whole strain population were found within any of the five groups of strains that behaved abnormally in the presumptive identification tests, ie, within the hippurate negative, CAMP negative, pigment negative, bacitracin susceptible, or bile susceptible groups.

\section{Discussion}

The 371 isolates of group B haemolytic streptococci included in the survey were from a number of clinical conditions, in most of which group B streptococci have been reported previously. The present study was therefore confined to strains 


\begin{tabular}{|c|c|c|c|c|c|c|c|}
\hline \multirow[t]{2}{*}{ Antibiotic } & \multicolumn{7}{|c|}{ Minimum Inhibitory Concentration $(\mu \mathrm{g} / \mathrm{ml})$} \\
\hline & $0 \cdot 05$ & 0.2 & $0 \cdot 8$ & $3 \cdot 1$ & $12 \cdot 5$ & 50 & $>50$ \\
\hline $\begin{array}{l}\text { Penicillin G } \\
\text { Ampicillin } \\
\text { Cephalothin } \\
\text { Erythromycin } \\
\text { Tetracycline }\end{array}$ & $\begin{array}{r}218 \\
175 \\
2 \\
276 \\
-\quad\end{array}$ & $\begin{array}{r}60 \\
104 \\
263 \\
3 \\
2\end{array}$ & $\frac{1}{\frac{14}{54}}$ & $\frac{-}{-}$ & $\frac{-}{-}$ & $\frac{-}{\overline{-}}$ & $\frac{-}{-}$ \\
\hline
\end{tabular}

Table II Minimum inhibitory concentrations of five antibiotics for 279 isolates of group $B$-haemolytic streptococci

thought to be causing disease. These isolates were subjected to presumptive identification tests not used in the selection of the strains; non-haemolytic group B streptococci were not included.

Among the 259 group B streptococci tested, 10 did not hydrolyse sodium hippurate detectably. Thus the hippurate test would have detected $96.1 \%$ of the present strains. Using stock cultures, Ferrieri et al (1973) found hydrolysis of sodium hippurate in $100 \%$ of strains, and Facklam et al (1974) in $99.6 \%$. Our technique may have been less sensitive, since trace precipitations were regarded as negative. It is also possible that the strains used in the previous series were selected, since the reports failed to indicate whether presumptive tests had been performed before sending the streptococci to the culture collections.

Originally, the CAMP reaction was found to detect $100 \%$ of group B streptococci (MunchPetersen et al, 1945), but in later studies its sensitivity settled to an average of $98.4 \%$ (Barnum, 1950; Esseveld et al, 1958; Biechteler, 1964; Pulverer, 1967; Heeschen et al, 1967), compared with $95.0 \%$ in the present investigation.

Although pigment production, also, is not a new observation, its use in the presumptive identification of group B streptococci has received little attention. Of 189 group B strains studied, Plummer (1941) found pigment production in $126(67 \%)$. Haemolysin was formed by 137 of the strains, but the possible association of haemolysin and pigment formation was not indicated. Fallon (1974) found pigment production in $86 \%$ of 63 strains of group B haemolytic streptococci on primary isolation under anaerobic conditions; none of the non-haemolytic group B strains studied produced pigment. In the present series, $97.3 \%$ of 295 strains of group B haemolytic streptococci produced pigment.

Negative results were infrequent in each of the three presumptive tests, and the simultaneous use of any two tests would have detected more than $99.8 \%$ of group B haemolytic streptococci. Each test has features that may be inconvenient for the clinical laboratory: the hippurate test requires two days, the CAMP test is performed on sheep or bovine blood agar, and pigment production requires anaerobic incubation and does not detect non-haemolytic strains. The choice of the test(s) for screening group B streptococci can therefore be based on convenience rather than sensitivity. In the present study, the specificity of the three presumptive tests in relation to haemolytic streptococci of other Lancefield groups was not investigated, but this may also guide the choice. Hippurate hydrolysis has been found with $6.9 \%$ of group D enterococci, none of group A streptococci, and $0.3 \%$ of groups other than A, B, or $\mathrm{D}$ (Facklam et al, 1974). Thus the test is expected to be highly specific for group B streptococci, if enterococci can be excluded. Slightly over $20 \%$ of group A streptococci have been reported CAMP positive (Heeschen et al, 1967; Lütticken and Fritsche, 1974). Fallon (1974) found that all pigment-producing streptococci were of group B, which is also our experience so far, but we are not aware of systematic studies of the specificity of pigment production. Comparable figures of the specificity of the three tests are not available, and will be hard to obtain, mainly because they are completely dependent on the distribution of the various serological groups in the material studied.

Growth on bile esculin agar without esculin hydrolysis was present in $99.0 \%$ of group B strains. Whether this property is sufficiently specific to be of any practical value in presumptive identification should be further studied, since this test will often be performed because of the resemblance of group B and enterococcal colonies.

The in vitro antibiotic susceptibility of group B streptococci was similar to that published more than 10 years ago (Eickhoff et al, 1964). All the 279 strains studied were susceptible to penicillin $\mathbf{G}$, ampicillin, cephalothin, and erythromycin, while most strains were resistant to tetracycline. Thus routine susceptibility testing of group B isolates may not be needed, although erythromycin resistant strains have been found previously (Eickhoff $e t a l$, 1964; Jokipii and Jokipii, unpublished).

The authors are grateful for the excellent technical assistance of Mrs Anita Mutanen and for support from the Paulo Foundation. 


\section{References}

Ayers, S. H. and Rupp, P. (1922). Differentiation of hemolytic streptococci from human and bovine sources by the hydrolysis of sodium hippurate. J. infect. Dis., 30, 388-399.

Barnum, D. A. (1950). The use of the CAMP test for the rapid identification of Streptococcus agalactiae. Rep. Ontario vet. Coll., pp. 120-125.

Biechteler, W. (1964). Beitrag zur Routine-Diagnostik hämolysierender Streptokokken (OBF-Test nach Guthoff, CAMP-Test, Antibiogramm). Zbl. Bakt., I Abt. Orig., 193, 48-56.

Christie, R., Atkins, N. E., and Munch-Petersen, E. (1944). A note on a lytic phenomenon shown by group B streptococci. Aust. J. exp. Biol. med. Sci., 22, 197-200.

Duma, R. J., Weinberg, A. N., Medrek, T. F., and Kunz, L. J. (1969). Streptococcal infections: a bacteriologic and clinical study of streptococcal bacteremia. Medicine (Baltimore), 48, 87-127.

Eickhoff, T. C. (1972). Group B streptococci in human infection. In Streptococci and Streptococcal Diseases, edited by L. W. Wannamaker, and J. M. Matsen, pp. 533-541. Academic Press, New York.

Eickhoff, T. C., Klein, J. O., Daly, A. K., Ingall, D., and Finland, M. (1964). Neonatal sepsis and other infections due to group B beta-hemolytic streptococci. New Engl. J. Med., 271, 1221-1228.

Esseveld, H., Daniëls-Bosman, M. S. M., and Leijnse, B. (1958). Some observations about the CAMP reaction and its application to human $\beta$-haemolytic streptococci. Antonie v. Leeuwenhoek, 24, 145-156.

Facklam, R. R., Padula, J. F., Thacker, L. G., Wortham, E. C., and Sconyers, B. J. (1974). Presumptive identification of group A, B, and D streptococci. Appl. Microbiol., 27, 107-113.

Fallon, R. J. (1974). The rapid recognition of Lancefield group B haemolytic streptococci. J. clin. Path., 27, 902-905.

Ferrieri, P., Wannamaker, L. W., and Nelson, J. (1973). Localization and characterization of the hippuricase activity of group B streptococci. Infect. Immunol., 7, 747-752.

Franciosi, R. A., Knostman, J. D., and Zimmerman, R. A. (1973). Group B streptococcal neonatal and infant infections. J. Pediat., 82, 707-718.

Heeschen, W., Tolle, A., and Zeidler, H. (1967). Zur Klassifizierung der Gattung Streptococcus. Zbl. Bakt., I Abt. Orig., 205, 250-259.

Jelínková, J., Neubauer, M., and Duben, J. (1970). Group B streptococci in human pathology. Zbl. Bakt., I Abt. Orig., 214, 450-457.

Lütticken, R. and Fritsche, D. (1974). Bestimmung der BStreptokokken (Streptococcus agalactiae) mit Hilfe des "Dreifachtests" nach Wallerström und des CAMP-Tests. Zbl. Bakt., I Abt. Orig., 226, 298-304.

Maxted, W. R. (1953). The use of bacitracin for identifying group A haemolytic streptococci. J. clin. Path., 6, 224-226.

Munch-Petersen, E., Christie, R., and Simmons, R. T. (1945). Further notes on a lytic phenomenon shown by group $B$ streptococci. Aust. J. exp. Biol. med. Sci., 23, 193-195.

Plummer, H. (1941). A serological and biochemical study of hemolytic streptococci. J. Immunol., 42, 91-107.

Pulverer, G. (1967). Gruppendifferenzierung beta-hämolysierender Streptokokken mit Hilfe des OBF-Testes nach Guthof und des CAMP-Testes. Zbl. Bakt., I Abt. Orig., 204, 301-304.

Swan, A. (1954). The use of a bile-aesculin medium and of Maxted's technique of Lancefield grouping in the identification of enterococci (group D streptococci). J. clin. Path., 7, 160-163.

Swift, H. F., Wilson, A. T., and Lancefield, R. C. (1943). Typing group $\mathbf{A}$ hemolytic streptococci by $\mathbf{M}$ precipitin reactions in capillary pipettes. J. exp. Med., 78, 127-133. 